\title{
A Golf Ball and A Bouncy Ball, Which Bounces Higher and Why
}

\author{
Kate Boydston, Cecil Ossa-Jaen, Anying (Daisy) Wang, Mengyao (Michelle) Zhao and Mr. Jim \\ Centorino
}

Sometimes, even the simple brightly-colored toys we all enjoyed as children can surprise us. In November of 2017 the AP Physics I class at Louisville High School (Kate Boydston, Cecil Ossa-Jaen, Daisy Wang, and Michelle Zhao) set out to delve deeper into the theoretical world of a recently released AP Physics I free response question relating to a "nearly elastic" bouncy ball. The question refers to designing an experiment to see if collisions at low speeds are more elastic than collisions at high speeds.

Keywords: golf ball, bouncy ball, drop height, variances

While the question only asks about a bouncy toy ball, we came to wonder how a golf ball of similar size might compare. We all hypothesized that the bouncy ball would prove to be more elastic due to our memories of excitement and wonder at the ball that could fly all over the room if thrown hard enough. Surely the pliable rubber would prove more bouncy that the hard ceramic-like golf ball. However, despite what we, and many others, might guess, this proved to be incorrect. As a room of prospective scientists and engineers, our next action was automatic: to create an experiment to test and explain this seemingly miraculous behavior.

We all agreed that the key to understanding the bouncy ball's odd lack of comparative elasticity was in measuring how high each ball bounced back when dropped from a certain height. With only a \#4 Titleist golf ball ${ }^{\mathrm{TM}}$, large rubber bouncy ball, meter stick, stopwatch, and four sets of eyes it was not difficult to develop a procedure to answer our many questions. We first placed a meter stick perpendicular to the floor and chose four heights to drop both balls from: $25 \mathrm{~cm}, 50 \mathrm{~cm}, 75 \mathrm{~cm}$, and $100 \mathrm{~cm}$. We dropped each ball five times from each of the four heights and recorded the bounce back height each time. A video camera could be used, but since there were four of us and we were all actively watching we decided to simplify the process by using our eyes instead.

Table 1: This table compares the bounce back heights, average speeds, and \% of bounce back when dropped from different original heights for the bouncy ball.

\begin{tabular}{|r|l|l|l|l|}
\hline & $25 \mathrm{~cm}(0.25 \mathrm{~m})$ & $50 \mathrm{~cm}(0.5 \mathrm{~m})$ & $75 \mathrm{~cm}(0.75 \mathrm{~m})$ & $100 \mathrm{~cm}(1 \mathrm{~m})$ \\
\hline Bounce Back 1 & $\begin{array}{l}16.5 \mathrm{~cm} \\
(0.1650 \mathrm{~m})\end{array}$ & $\begin{array}{l}38.0 \mathrm{~cm} \\
(0.3800 \mathrm{~m})\end{array}$ & $\begin{array}{l}54.0 \mathrm{~cm} \\
(0.5400 \mathrm{~m})\end{array}$ & $\begin{array}{l}72.0 \mathrm{~cm} \\
(0.7200 \mathrm{~m})\end{array}$ \\
\hline 2 & $\begin{array}{l}18.0 \mathrm{~cm} \\
(0.1800 \mathrm{~m})\end{array}$ & $\begin{array}{l}37.0 \mathrm{~cm} \\
(0.3700 \mathrm{~m})\end{array}$ & $\begin{array}{l}53.0 \mathrm{~cm} \\
(0.5300 \mathrm{~m})\end{array}$ & $\begin{array}{l}73.0 \mathrm{~cm} \\
(0.7300 \mathrm{~m})\end{array}$ \\
\hline 3 & $\begin{array}{l}17.0 \mathrm{~cm} \\
(0.1700 \mathrm{~m})\end{array}$ & $\begin{array}{l}37.5 \mathrm{~cm} \\
(0.3750 \mathrm{~m})\end{array}$ & $\begin{array}{l}54.0 \mathrm{~cm} \\
(0.5400 \mathrm{~m})\end{array}$ & $\begin{array}{l}73.5 \mathrm{~cm} \\
(0.7350 \mathrm{~m})\end{array}$ \\
\hline 4 & $\begin{array}{l}16.0 \mathrm{~cm} \\
(0.1600 \mathrm{~m})\end{array}$ & $\begin{array}{l}37.5 \mathrm{~cm} \\
(0.3750 \mathrm{~m})\end{array}$ & $\begin{array}{l}54.5 \mathrm{~cm} \\
(0.5450 \mathrm{~m})\end{array}$ & $\begin{array}{l}72.0 \mathrm{~cm} \\
(0.7200 \mathrm{~m})\end{array}$ \\
\hline 5 & $\begin{array}{l}17.0 \mathrm{~cm} \\
(0.1700 \mathrm{~m})\end{array}$ & $\begin{array}{l}37.0 \mathrm{~cm} \\
(0.3700 \mathrm{~m})\end{array}$ & $\begin{array}{l}5.0 \mathrm{~cm} \\
(0.5500 \mathrm{~m})\end{array}$ & $\begin{array}{l}70.0 \mathrm{~cm} \\
(0.7000 \mathrm{~m})\end{array}$ \\
\hline Avg. Bounce Back & $\begin{array}{l}16.9 \mathrm{~cm} \\
(0.169 \mathrm{~m})\end{array}$ & $\begin{array}{l}37.4 \mathrm{~cm} \\
(0.374 \mathrm{~m})\end{array}$ & $\begin{array}{l}54.1 \mathrm{~cm} \\
(0.541 \mathrm{~m})\end{array}$ & $\begin{array}{l}72.1 \mathrm{~cm} \\
(0.721 \mathrm{~m})\end{array}$ \\
\hline
\end{tabular}

a. Department of Physics, Louisville High School, Woodland Hills, CA, 91364 
Table 2: This table compares the bounce back heights, average speeds, and \% of bounce back when dropped from different original heights for the golf ball.

\begin{tabular}{|l|l|l|l|l|}
\hline & $25 \mathrm{~cm}(0.25 \mathrm{~m})$ & $50 \mathrm{~cm}(0.5 \mathrm{~m})$ & $75 \mathrm{~cm}(0.75 \mathrm{~m})$ & $100 \mathrm{~cm}(1 \mathrm{~m})$ \\
\hline Bounce Back 1 & $\begin{array}{l}19.0 \mathrm{~cm} \\
(0.1900 \mathrm{~m})\end{array}$ & $\begin{array}{l}39.0 \mathrm{~cm} \\
(0.3900 \mathrm{~m})\end{array}$ & $\begin{array}{l}60.0 \mathrm{~cm} \\
(0.6000 \mathrm{~m})\end{array}$ & $\begin{array}{l}77.0 \mathrm{~cm} \\
(0.7700 \mathrm{~m})\end{array}$ \\
\hline 2 & $\begin{array}{l}17.0 \mathrm{~cm} \\
(0.1700 \mathrm{~m})\end{array}$ & $\begin{array}{l}38.0 \mathrm{~cm} \\
(0.3800 \mathrm{~m})\end{array}$ & $\begin{array}{l}57.5 \mathrm{~cm} \\
(0.5750 \mathrm{~m})\end{array}$ & $\begin{array}{l}79.0 \mathrm{~cm} \\
(0.7900 \mathrm{~m})\end{array}$ \\
\hline 3 & $\begin{array}{l}19.0 \mathrm{~cm} \\
(0.1900 \mathrm{~m})\end{array}$ & $\begin{array}{l}37.0 \mathrm{~cm} \\
(0.3700 \mathrm{~m})\end{array}$ & $\begin{array}{l}58.5 \mathrm{~cm} \\
(0.5850 \mathrm{~m})\end{array}$ & $\begin{array}{l}78.0 \mathrm{~cm} \\
(0.7800 \mathrm{~m})\end{array}$ \\
\hline 4 & $\begin{array}{l}17.5 \mathrm{~cm} \\
(0.175 \mathrm{~m})\end{array}$ & $\begin{array}{l}40.0 \mathrm{~cm} \\
(0.400 \mathrm{~m})\end{array}$ & $\begin{array}{l}59.5 \mathrm{~cm} \\
(0.595 \mathrm{~m})\end{array}$ & $\begin{array}{l}78.0 \mathrm{~cm} \\
(0.780 \mathrm{~m})\end{array}$ \\
\hline 5 & $\begin{array}{l}17.5 \mathrm{~cm} \\
(0.175 \mathrm{~m})\end{array}$ & $\begin{array}{l}39.0 \mathrm{~cm} \\
(0.390 \mathrm{~m})\end{array}$ & $\begin{array}{l}60.0 \mathrm{~cm} \\
(0.600 \mathrm{~m})\end{array}$ & $\begin{array}{l}79.0 \mathrm{~cm} \\
(0.790 \mathrm{~m})\end{array}$ \\
\hline Avg. Bounce Backk & $\begin{array}{l}18 \mathrm{~cm} \\
(0.180 \mathrm{~m})\end{array}$ & $\begin{array}{l}38.6 \mathrm{~cm} \\
(0.386 \mathrm{~m})\end{array}$ & $\begin{array}{l}58.7 \mathrm{~cm} \\
(0.587 \mathrm{~m})\end{array}$ & $\begin{array}{l}78.2 \mathrm{~cm} \\
(0.782 \mathrm{~m})\end{array}$ \\
\hline Avg. Speed & $1.11 \mathrm{~m} / \mathrm{s}$ & $1.57 \mathrm{~m} / \mathrm{s}$ & $1.92 \mathrm{~m} / \mathrm{s}$ & $2.21 \mathrm{~m} / \mathrm{s}$ \\
\hline Bounce Back \% & $72 \%$ & $77.2 \%$ & $78.27 \%$ & $78.2 \%$ \\
\hline
\end{tabular}

\begin{tabular}{|l|l|l|}
\hline Mass $(\mathrm{g}, \mathrm{kg})$ & $45.75 \mathrm{~g}$ & $0.04575 \mathrm{~kg}$ \\
\hline Volume $\left(\mathrm{cm}^{\wedge} 3, \mathrm{~m}^{\wedge} 3\right)$ & $45 \mathrm{~cm}^{\wedge} 3$ & $4.5 * 10^{\wedge}-5 \mathrm{~m}^{\wedge} 3$ \\
\hline Dens ity $\left(\mathrm{g} / \mathrm{cm}^{\wedge} 3\right)\left(\mathrm{kg} / \mathrm{m}^{\wedge} 3\right)$ & $1.017 \mathrm{~g} / \mathrm{cm}^{\wedge} 3$ & $1017 \mathrm{~kg} / \mathrm{m}^{\wedge} 3$ \\
\hline
\end{tabular}

After the five bounce back heights were recorded for each height and both balls we calculated the average bounce back height, the average speed for each drop height (which was the same for both balls since the acceleration of gravity is the same regardless of mass or weight), and the percent of the original height the bounce back height was (average bounce back height / drop height). Furthermore, we used a scale to measure the mass of the golf ball and the bouncy ball and calculated the volume and density of each. With this collection of data, we were able to observe some very interesting trends.

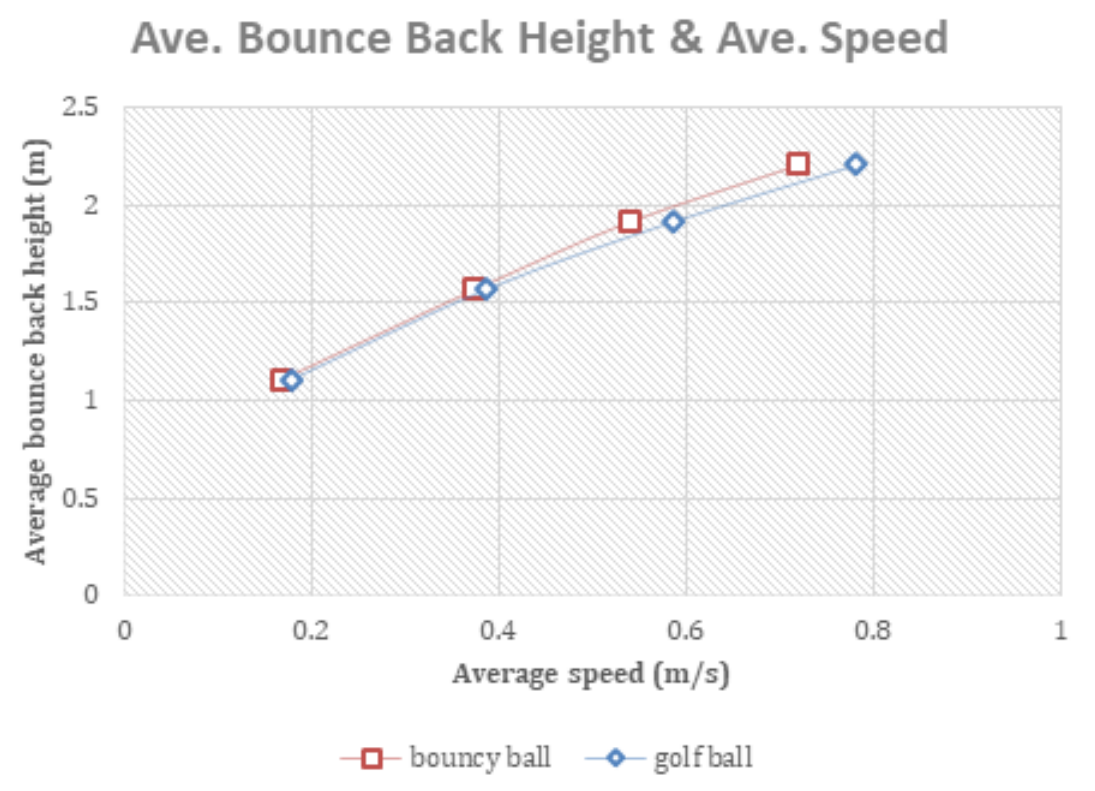

Figure 3. The results of the tables in table 1 and table 2 were graphed in this figure. The trends were similar. 


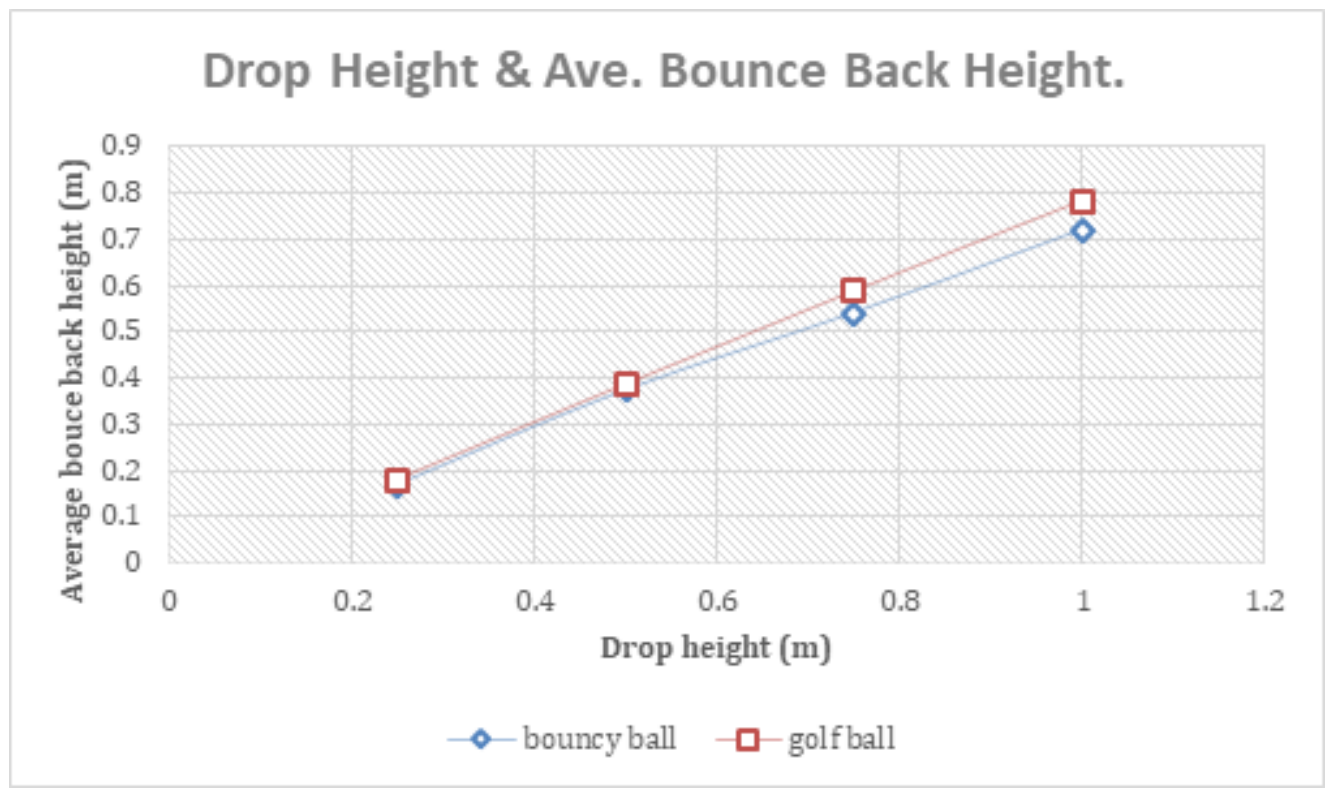

Figure 2. The results of the tables in table 1 and table 2 were graphed in this figure. The trends were similar.

Despite what we expected the golf ball bounced higher than the bouncy ball when dropped from rest under identical conditions. We have come to realize that this must be because the bouncy ball is less dense than the golf ball. Our most startling data however were the following:

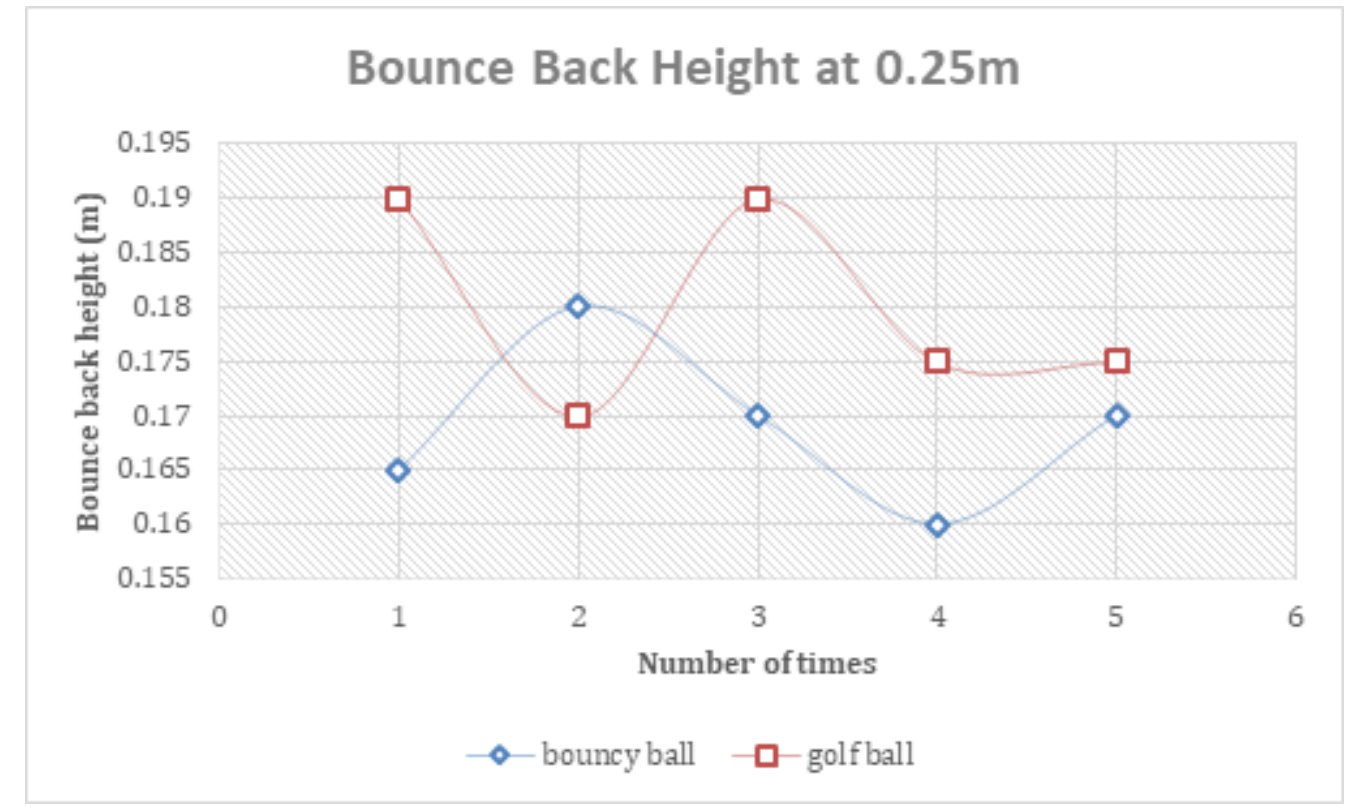

Figure 3. In this figure we noted variances in the bounce back heights from $0.25 \mathrm{~m}$ for both the bouncy ball and the golf ball. 


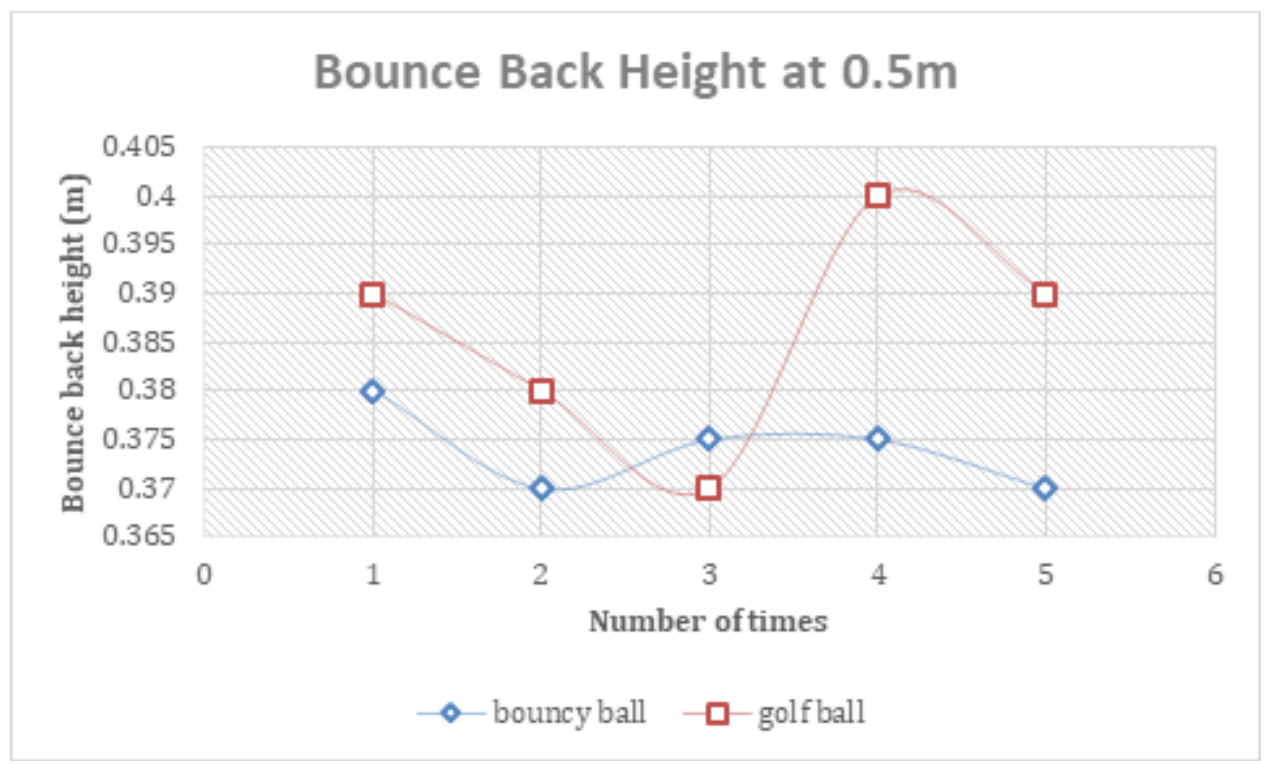

Figure 4. In this figure we noted variances in the bounce back heights from $0.50 \mathrm{~m}$ for both the bouncy ball and the golf ball.

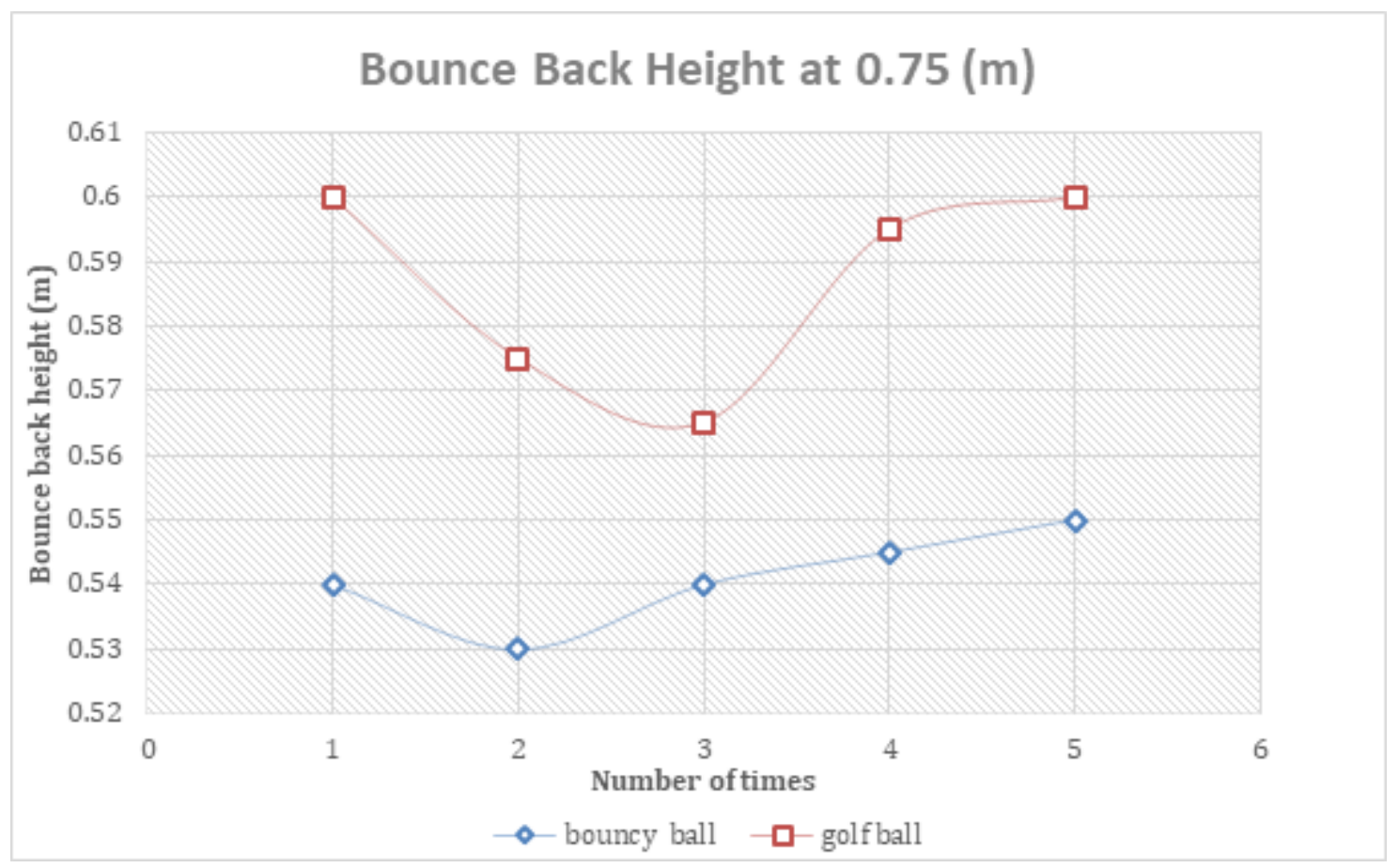

Figure 5. In this figure we noted variances in the bounce back heights from $0.75 \mathrm{~m}$ for both the bouncy ball and the golf ball. 


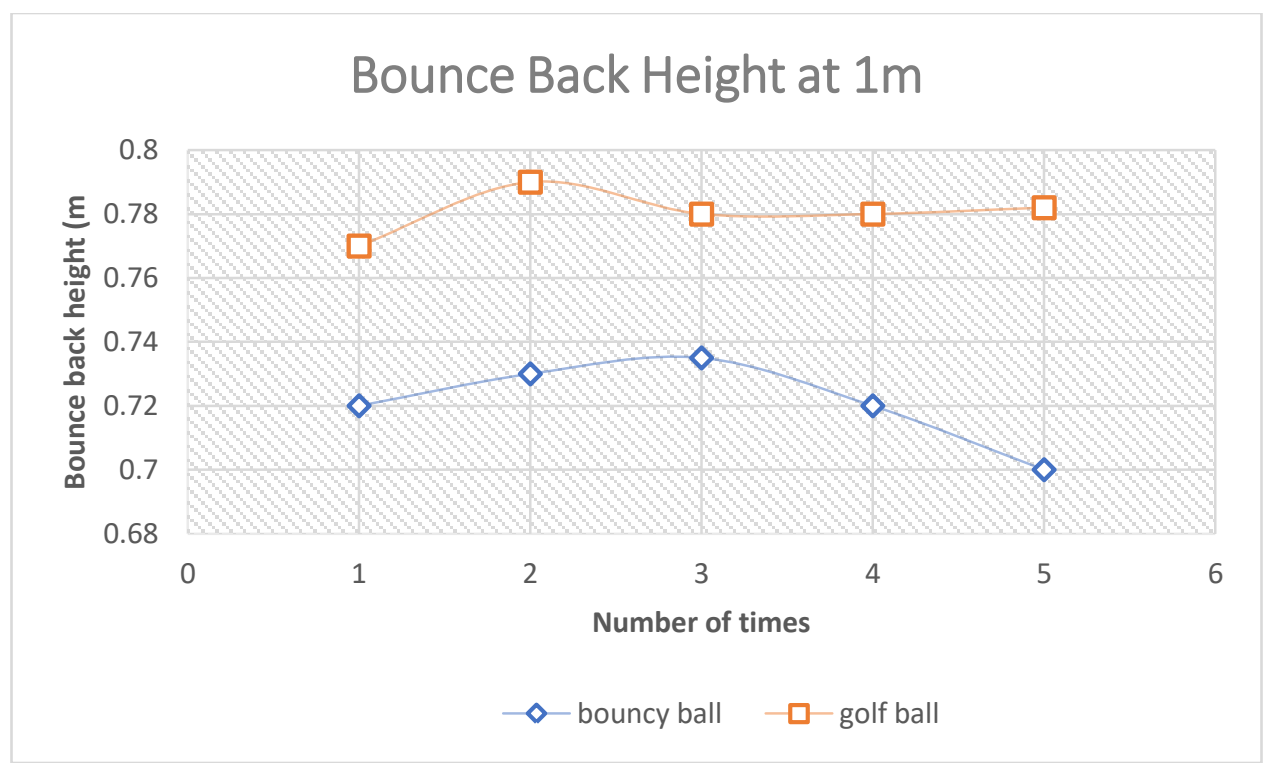

Figure 6. In this figure we noted variances in the bounce back heights from $0.75 \mathrm{~m}$ for both the bouncy ball and the golf ball.

The consistency of bounce back height increased with initial drop height. This must be due to sources of error. This could include the ruler moving slightly between trials, mistaken height recordings due to human error in seeing bounce back height, or a slightly uneven floor.

Even with human error, these results all show one thing: the \#4 Titleist Golf Ball definitely bounces higher than the bouncy ball as a result of its less flexible surface and denser nature. 